\title{
FUTURE Act to advance clean energy through Carbon Capture Utilization and Storage
}

\author{
By Felicia Lucci
}

A nalysts recently proposed an ambitious roadmap to maintain global temperatures within $2^{\circ} \mathrm{C}$ of preindustrial levels. To reach this goal, greenhouse gas emissions would need to be reduced by half every decade until 2050 (Science, doi:10.1126/science.aah3443). However, with greenhouse gas emissions increasing by $2.2 \%$ annually from 2000 to 2010 , how economically feasible is it to mitigate global warming? Experts and analysts, including the International Energy Agency and the UN Intergovernmental Panel on Climate Change (IPCC) specify the development of Carbon Capture Utilization and Storage (CCUS) technology to address $\mathrm{CO}_{2}$ emissions will be necessary to efficiently and economically achieve the greenhouse gas emissions target laid out in the Paris Climate Agreement. Currently, the United States receives $65 \%$ of its electricity from fossil fuels, which emits 5171 million metric tons of $\mathrm{CO}_{2}$ annually.

Although renewable energy is steadily growing and predicted to account for $28 \%$ of global electricity production by 2021, it is anticipated that global energy consumption will increase faster than renewable energy growth. In reality, coal and naturalgas-fired power plants will be part of the electricity mix for the foreseeable future due to its relative abundance and affordability. Without CCUS technology, according to IPCC, it will cost USD\$3.5 trillion more to decarbonize the power sector by mid-century. In the near term, CCUS can address $\mathrm{CO}_{2}$ emissions from point sources, including coal and natural-gas-fired electricity plants and industrial processes such as cement, steel, and chemical manufacturing. Eventually, CCUS, coupled with additional technologies, will be needed to achieve negative $\mathrm{CO}_{2}$ emissions by actively removing $\mathrm{CO}_{2}$ from the atmosphere.

The inclusion of CCUS technologies on power plants requires large investments in capital equipment and increases the operating cost of power plants while reducing the overall generation. Due to the added expense of CCUS - outside of generating revenue through limited enhanced oil recovery opportunities - no incentives are currently in place in the United States for utilities and industries to capture $\mathrm{CO}_{2}$ emissions. Without carbon regulations, it is simply less expensive to release $\mathrm{CO}_{2}$ into the air than to capture it. When considering the necessity to develop CCUS technology to address $\mathrm{CO}_{2}$ emissions in both the short and long term, policies are needed to incentivize investment in CCUS technology.

CCUS is the only technology capable of removing $\mathrm{CO}_{2}$ emissions from point sources at a capturing capability of up to $90 \%$. CCUS is a simple concept where $\mathrm{CO}_{2}$ is extracted from the emission of a stationary source and then transported to be either stored in secure geological formations or utilized in enhanced oil recovery or other industrial processes. From a technological viewpoint, each step is theoretically feasible and based on industrial practices. For example, capturing $\mathrm{CO}_{2}$ using an amine scrubbing process has been patented since 1930. However, regeneration of the amine solution is an energy-intensive process. Thus, inclusion of carbon capture on a power plant can reduce the overall electricity output by $30 \%$. Furthermore, CCUS projects are expensive to build and are currently estimated to increase capital expenditure of a new power plant by $30-80 \%$, resulting in fewer commercialscale CCUS power plants worldwide. Thus, current research and development efforts focus on improving the efficiency of the processes and reducing the overall costs of capital equipment. To substantially reduce the costs of the projects, further commercial-scale deployment is needed.

The US Department of Energy (DOE) has been investing in CCUS technology for the last 20 years. The research has made advances, including reducing the energy penalty of the $\mathrm{CO}_{2}$ capture process and verifying permanent $\mathrm{CO}_{2}$ storage in deep saline formations. Currently, DOE funding is playing a critical role in deploying largescale pilot projects and commercial scale demonstration plants. However, the current administration's proposed 2018 fiscal budget reduces funding for CCUS programs by more than $80 \%$, reflecting a shift to prioritize early stage research projects. Final congressional appropriations for the DOE will greatly influence the future role of the United States in developing this technology.

CCUS has broad bipartisan support in Congress, as demonstrated by a key bill to incentivize CCUS. The FUTURE Act (Furthering carbon capture, Utilization, Technology, Underground storage, and Reduced Emissions), introduced in July 2017 by Senator Heidi Heitkamp (D-N.D.), would improve upon a tax credit for carbon capture and storage of $\mathrm{CO}_{2}$. Under Section 45Q of the federal statutory tax code, tax credits are provided for the capture and disposal of $\mathrm{CO}_{2}$. However, the current tax credit is insufficient to stimulate significant investment in CCUS due to the high cost of capital investments. Heitkamp's bill increases the value of the credit to better assist financing of projects, and expands the credit to include utilization of $\mathrm{CO}_{2}$ beyond enhanced oil recovery.

Heitkamp sees the technology as a path forward for domestic energy resources, such as coal and natural gas, by spurring adoption of low-carbon technologies and providing economic opportunity from the commercialization of the technology and transforming carbon pollution into a valuable product. Both the economic and environmental impacts presented by CCUS have yielded support across the political spectrum, reflected in co-sponsors of the bill, including climate advocate Senator Sheldon Whitehouse (D-R.I.) and avid coal supporters, Senators Shelley Moore Capito (R-W.Va.) and John Barrasso (R-Wyo.). 